\title{
Pengaruh warna umpan pada hasil tangkapan pancing tonda di perairan Teluk Manado Sulawesi Utara
}

\author{
The effect of bait color on catch of trolling line in Manado Bay, North Sulawesi \\ FYCKI FENDI IMBIR, WILHELMINA PATTY* dan JOHNY WENNO \\ Program Studi Pemanfaatan Sumberdaya Perikanan, Fakultas Perikanan dan Ilmu Kelautan, \\ Universitas Sam Ratulangi, Manado 95115
}

\begin{abstract}
Fishery potential in Manado Bay, especially capture fisheries is quite large; but fishing activities that carried out by fishermen are still relatively in small scale; which is dominated by various types of hook and line, and small purse seine. Trolling is a traditional fishing gear that commonly used by fishermen in Manado Bay to catch pelagic fish species with artificial bait. This research aimed to study the effect of artificial bait color on the catch of trolling; and to identify the fish species. This research was conducted in January 2015 based on the experimental method. Two types of artificial bait colors were used, i.e. blue and pink; artificial bait was made of silk fibers. Catch data collected using small boats Pelang types, with 2 units of trolling line; operated during daylight from the morning (06:00 Wita) until the afternoon (18:00 Wita), data recorded every 2 hours for two days; and the data were analyzed using t-test. The catch of trolling line consists of Auxis thazard $(0.2 \mathrm{~kg})$, Selar sp $(0.1 \mathrm{~kg})$ and Katsuwonus pelamis $(1.54 \mathrm{~kg})$. Results of the analysis showed that the use of blue artificial bait on trolling caught more fish than that of pink artificial bait.
\end{abstract}

Keywords: trolling line, artificial bait, Manado Bay

\begin{abstract}
ABSTRAK
Produksi perikanan di Teluk Manado terutama perikanan tangkap cukup besar; tetapi kegiatan perikanan yang dilakukan oleh nelayan adalah masih tergolong skala kecil; yang didominasi oleh berbagai jenis pancing dan pukat cincin kecil. Pancing tonda merupakan alat tangkap ikan tradisional yang umum dioperasikan oleh nelayan di Teluk Manado untuk menangkap jenis-jenis ikan pelagis dengan umpan buatan. Penelitian ini ditujukan untuk untuk mempelajari pengaruh warna umpan buatan terhadap hasil tangkapan pancing tonda; dan mengidentifikasi jenisjenis ikan yang tertangkap. Penelitian ini dilakukan pada bulan Januari 2015 yang menggunakan metode eksperimental. Dua jenis warna umpan buatan yang digunakan, yaitu biru dan merah muda terbuat dari serat sutera. Data tangkapan dikumpulkan menggunakan 1 unit perahu tipe pelang dan 2 unit pancing tonda; dioperasikan sejak pagi hari (pukul 06.00 Wita) hingga sore hari (pukul 18:00 Wita), pencatatan data setiap 2 jam. selama dua hari; data dianalisis dengan uji t. Hasil tangkapan pancing tonda terdiri dari Auxis thazard dengan berat rata-rata $0.2 \mathrm{~kg}$, Selar $s p(0,1 \mathrm{~kg})$ dan Katsuwonus pelamis $(1.54 \mathrm{~kg})$. Hasil analisis menunjukkan bahwa penggunaan umpan buatan warna biru pada pancing tonda memberikan hasil tangkapan yang lebih banyak dibandingkan dengan umpan buatan warna merah muda.
\end{abstract}

Kata-kata kunci: pancing tonda, umpan buatan, Teluk Manado

\section{PENDAHULUAN}

Sebahagian besar nelayan di Kota Manado memiliki usaha yang masih termasuk usaha skala kecil yang didominasi oleh penangkapan ikan dengan mini purse seine, pole and line dan

\footnotetext{
* Penulis untuk penyuratan; email:

Wilhelmina.patty@yahoo.com
}

berbagai alat tangkap pancing lainnya seperti pancing tonda. Pancing tonda ini merupakan alat tangkap ikan tradisional yang memakai umpan tiruan untuk mengelabui penglihatan ikan dan umumnya untuk menangkap jenis-jenis ikan pelagis. Agar suatu benda dalam air dapat terlihat tergantung dari kemampuan retina mata untuk menyerap warna yang dipantulkan oleh benda 
tersebut. Oleh sebab itu pemilihan warna umpan sangat menentukan keberhasilan memancing di laut.

Berdasarkan permasalahan di atas, maka dalam penelitian ini dapat dicoba dengan memberi perlakuan terhadap alat tangkap pancing Tonda yaitu penggunaan umpan buatan warna biru dan merah muda untuk mengetahui dan menganalisis pengaruh warna umpan buatan terhadap hasil tangkapan di perairan Teluk Manado serta mengidentifikasi jenis-jenis ikan yang tertangkap.

\section{METODE PENELITIAN}

Penelitian ini dilakukan di perairan Teluk Manado pada bulan Januari 2015 yang didasarkan pada metode eksperimental dengan menggunakan 1 unit perahu tipe pelang dan 2 unit pancing tonda dengan 2 warna umpan buatan yang berbeda yang dioperasikan pada pagi hari (pukul 06.00 Wita) hingga sore hari (pukul 18:00 Wita). Dua warna umpan buatan yang dijadikan sebagai perlakuan adalah warna biru (variabel $\mathrm{X}$ ) dan warna merah muda (variabel Y).

Data yang dikumpulkan adalah komposisi serta ukuran panjang dan berat hasil tangkapan. Hasil pengamatan dikelompokkan menurut waktu pengamatan (setiap 2 jam), selanjutnya data dianalisis dengan menggunakan analisis komparatif dua sampel berkorelasi yakni uji nilai tengah (t student), untuk mengetahui ada atau tidaknya pengaruh penggunaan warna umpan biru dan merah muda terhadap hasil tangkapan.

\section{HASIL DAN PEMBAHASAN}

\section{Hasil tangkapan}

Hasil tangkapan yang diperoleh selama dua hari pengambilan data berjumlah masing-masing 19 ekor dan 16 ekor (Tabel 1 dan 2). Pada hari pertama, jumlah ikan yang tertangkap relatif lebih banyak (1-4 ekor) baik menurut waktu pengamatan maupun warna umpan dibandingkan dengan hari kedua (1sampai 3 ekor).

Sebahagian besar ikan yang tertangkap pada hari pertama dijumpai pada waktu antara pukul 10.00 Wita sampai pukul 16.00 Wita. Pada saat itu posisi daerah penangkapan adalah di sekitar rumpon. Posisi geografis lokasi penangkapan ini berada pada $01^{\circ} 28,18.6^{\prime \prime}-01^{\circ} 29$ '39.9" $\mathrm{N}$ dan $124^{\circ} 48^{\prime} 06.5^{\prime \prime}-124^{\circ} 48^{\prime} 31.6^{\prime \prime} \mathrm{E}$.

Menurut Monintja dan Sukarnaen (1995), rumpon merupakan konstruksi bangunan yang dipasang di dalam air dengan tujuan untuk memikat ikan agar berasosiasi dengannya sehingga memudahkan penangkapan ikan tersebut. Asosiasi ikan merupakan salah satu tingkah laku ikan yang penting bagi keberhasilan penangkapan ikan (Baskoro dkk., 2011).

Kondisi perairan pada sebahagian besar waktu pengamatan di hari pertama adalah angin dan bergelombang. Menurut Ferno dan Olsen (1994) bahwa arus berpengaruh pada hasil tangkapan pancing yang menggunakan umpan karena arus membuat ransangan penciuman dapat mendeteksi umpan pada jarak yang lebih jauh.

Jumlah hasil tangkapan dengan umpan warna biru relatif lebih banyak yakni dua sampai 3 kali lebih banyak dari umpan warna merah muda (Tabel 1 dan 2). Menurut Yami (1987) dalam Baskoro dan Suherman (2009) bahwa pengaruh cahaya terhadap hasil tangkapan tergantung pada daya tembus warna tersebut ke dalam perairan. Cahaya warna biru dapat mengumpulkan ikan pada jarak yang jauh baik secara vertikal maupun secara horizontal karena panjang gelombang yang lebih pendek dari cahaya hijau, kuning dan merah.

Tabel 1. Jumlah hasil tangkapan ikan (ekor) pada hari pertama menurut perlakuan warna umpan.

\begin{tabular}{ccccc}
\hline No & $\begin{array}{c}\text { Waktu Operasi Penangkapan } \\
\text { (Wita) }\end{array}$ & \multicolumn{2}{c}{ Perlakuan Warna Umpan } & \multirow{2}{*}{$\begin{array}{c}\text { Total } \\
\text { (ekor) }\end{array}$} \\
\cline { 2 - 4 } & $06.00-08.00$ & Biru & Merah Muda & 3 \\
2 & $08.05-10.00$ & 1 & 1 & 2 \\
3 & $10.05-12.00$ & 3 & 1 & 5 \\
4 & $12.05-14.00$ & 2 & 2 & 3 \\
5 & $14.05-16.00$ & 4 & 1 & 5 \\
6 & $16.05-18.00$ & 1 & - & 1 \\
\hline Total & & 13 & 6 & 19 \\
\hline
\end{tabular}


Tabel 2. Jumlah hasil tangkapan ikan (ekor) pada hari kedua menurut perlakuan warna umpan.

\begin{tabular}{|c|c|c|c|c|}
\hline \multirow[t]{2}{*}{ No } & \multirow{2}{*}{$\begin{array}{c}\text { Waktu Operasi Penangkapan } \\
\text { (Wita) }\end{array}$} & \multicolumn{2}{|c|}{ Perlakuan Warna Umpan } & \multirow{2}{*}{$\begin{array}{r}\text { Total } \\
\text { (ekor) }\end{array}$} \\
\hline & & Biru & Merah Muda & \\
\hline 1 & $06.00-08.00$ & 2 & 0 & 2 \\
\hline 2 & $08.05-10.00$ & 2 & 1 & 3 \\
\hline 3 & $10.05-12.00$ & 2 & 0 & 2 \\
\hline 4 & $12.05-14.00$ & 2 & 1 & 3 \\
\hline 5 & $14.05-16.00$ & 1 & 1 & 2 \\
\hline 6 & $16.05-18.00$ & 3 & 1 & 4 \\
\hline Total & & 12 & 4 & 16 \\
\hline
\end{tabular}

Tabel 3. Hasil tangkapan ikan dengan pancing tonda pada hari pertama.

\begin{tabular}{ccccl}
\hline No & Jenis Ikan & $\begin{array}{c}\text { Panjang Ikan } \\
(\mathrm{cm})\end{array}$ & $\begin{array}{c}\text { Berat Ikan } \\
(\mathrm{Kg})\end{array}$ & Cuaca \\
\hline 1 & Auxis thazard & 22 & 0,1 & Cerah \& Teduh \\
2 & Auxis thazard & 24 & 0,1 & Cerah \& Teduh \\
3 & Auxis thazard & 27 & 0,2 & Cerah \& Teduh \\
4 & Auxis thazard & 34 & 0,3 & Angin \& Gelombang \\
5 & Auxis thazard & 26 & 0,2 & Angin \& Gelombang \\
6 & Auxis thazard & 21 & 0,1 & Angin \& Gelombang \\
7 & Auxis thazard & 26 & 0,2 & Angin \& Gelombang \\
8 & Auxis thazard & 30 & 0,2 & Angin \& Gelombang \\
9 & Auxis thazard & 34 & 0,3 & Angin \& Gelombang \\
10 & Auxis thazard & 24 & 0,2 & Angin \& Gelombang \\
11 & Auxis thazard & 21 & 0,1 & Angin \& Gelombang \\
12 & Auxis thazard & 24 & 0,2 & Angin \& Gelombang \\
13 & Auxis thazard & 19 & 0,1 & Angin \& Gelombang \\
14 & Auxis thazard & 23 & 0,2 & Angin \& Gelombang \\
15 & Auxis thazard & 27 & 0,2 & Angin \& Gelombang \\
16 & Auxis thazard & 20 & 0,1 & Angin \& Gelombang \\
17 & Auxis thazard & 19 & 0,1 & Angin \& Gelombang \\
18 & Auxis thazard & 36 & 0,3 & Angin \& Gelombang \\
19 & Auxis thazard & 27 & 0,2 & Angin \& Gelombang \\
\hline Nilai Rata-Rata & 25.5 & 0,18 & \\
\hline
\end{tabular}

Jenis ikan yang tertangkap pada hari pertama semuanya adalah ikan tongkol (Auxis thazard). Ukuran panjang ikan berkisar antara $19-36 \mathrm{~cm}$ dengan panjang rata-rata adalah $25,5 \mathrm{~cm}$. Ukuran berat rata-rata ikan hasil tangkapan pada hari pertama adalah $0,18 \mathrm{~kg}$ (Tabel 3).

Pada hari kedua, operasi penangkapan dilakukan di lokasi sekitar rumpon dengan posisi geografis lokasi penangkapan $01^{\circ} 28^{\prime} 19.3$ '$01^{\circ} 34^{\prime} 04.8^{\prime \prime} \mathrm{N}$ dan $124^{\circ} 45^{\prime} 22.8^{\prime \prime}-124^{\circ} 48^{\prime} 25.7^{\prime \prime}$ E. Kondisi cuaca pada saat operasi penangkapan sebagian besar adalah berombak (Tabel 4).

Ada 3 jenis ikan yang tertangkap dengan pancing tonda pada hari kedua yakni Selar $s p(1$ ekor) dengan ukuran panjang $19 \mathrm{~cm}$ dan berat 0,1 $\mathrm{kg}$, ikan tongkol sebanyak 8 ekor dengan panjang berkisar antara $28-35 \mathrm{~cm}$ dan berat berkisar $0,2-0,5$ $\mathrm{kg}$ dan cakalang sebanyak 7 ekor dengan ukuran panjang berkisar 40-52 $\mathrm{cm}$ dan berat berkisar 1,0$2,8 \mathrm{~kg}$ (Tabel 4). Panjang rata-rata ikan Selar $s p$ adalah $19 \mathrm{~cm}$ dan berat $0,1 \mathrm{~kg}$, panjang rata-rata tongkol yang ditangkap adalah $29,8 \mathrm{~cm}$ dan berat rata-rata adalah $0,3 \mathrm{~kg}$. Untuk ikan cakalang yang ditangkap pada hari kedua memiliki panjang ratarata $44,43 \mathrm{~cm}$ dan berat rata-rata adalah $1,72 \mathrm{~kg}$. Hasil tangkapan ikan cakalang relatif lebih besar $(1-2,8 \mathrm{~kg})$ dan sebahagian besar dari mereka ditangkap dengan menggunakan warna umpan biru dan hanya 2 ekor yang ditangkap dengan warna umpan merah muda. Kondisi perairan pada saat itu adalah angin dan bergelombang. Menurut Hela dan Laevastu (1993) bahwa penyebaran ikan cakalang sering mengikuti penyebaran atau sirkulasi arus, terutama di lokasi pertemuan arus 
merupakan daerah yang banyak organisme dan diduga daerah tersebut merupakan fishing ground yang baik bagi perikanan cakalang.

\section{Hasil analisis}

Data hasil tangkapan selama 2 hari pengamatan dikelompokkan menurut waktu pengamatan dan dianalisis menurut perlakuan warna umpan yang berbeda (biru dan merah muda) untuk analisis uji t seperti terlihat pada pada Tabel 5. Hasil analisis menunjukkan bahwa t hitung $=4,56>\mathrm{t}$ tabel $\mathbf{0 , 0 1 ; 5}$ $=4,032$; sehingga menolak $\mathrm{H}_{0}$ dan menerima $\mathrm{H}_{1}$, di mana hal ini ini menjelasan bahwa penggunaan umpan buatan warna biru pada pancing tonda memberikan hasil tangkapan yang berbeda sangat nyata dibandingkan dengan umpan buatan warna merah muda.

Tabel 4. Hasil tangkapan ikan dengan pancing tonda pada hari kedua.

\begin{tabular}{clccl}
\hline No & \multicolumn{1}{c}{ Jenis Ikan } & $\begin{array}{c}\text { Ukuran Ikan } \\
(\mathrm{cm})\end{array}$ & $\begin{array}{c}\text { Berat Ikan } \\
(\mathrm{kg})\end{array}$ & \multicolumn{1}{c}{ Cuaca } \\
\hline 1 & Selar sp & 19 & 0,1 & Cerah \& Teduh \\
2 & Auxis thazard & 35 & 0,3 & Cerah \& Teduh \\
3 & Auxis thazard & 31 & 0,2 & Cerah \& Teduh \\
4 & Auxis thazard & 31 & 0,4 & Cerah \& Teduh \\
5 & Auxis thazard & 30 & 0,4 & Cerah \& Teduh \\
6 & Auxis thazard & 28 & 0,4 & Cerah \& Teduh \\
7 & Auxis thazard & 32 & 0,5 & Angin \& Gelombang \\
8 & Auxis thazard & 32 & 0,3 & Angin \& Gelombang \\
9 & Auxis thazard & 30 & 0,2 & Angin \& Gelombang \\
10 & Katsuwonus pelamis & 41 & 1,0 & Angin \& Gelombang \\
11 & Katsuwonus pelamis & 42 & 1,9 & Angin \& Gelombang \\
12 & Katsuwonus pelamis & 46 & 1,0 & Angin \& Gelombang \\
13 & Katsuwonus pelamis & 48 & 1,9 & Angin \& Gelombang \\
14 & Katsuwonus pelamis & 52 & 2,8 & Angin \& Gelombang \\
15 & Katsuwonus pelamis & 40 & 1,0 & Angin \& Gelombang \\
16 & Katsuwonus pelamis & 42 & 1,2 & Angin \& Gelombang \\
\hline
\end{tabular}

Tabel 5. Analisis uji t terhadap hasil tangkapan pancing tonda

\begin{tabular}{cccccc}
\hline No & $\begin{array}{c}\text { Waktu Operasi } \\
\text { Penangkapan (Wita) }\end{array}$ & $\begin{array}{c}\text { Umpan Warna } \\
\text { Biru (X) }\end{array}$ & $\begin{array}{c}\text { UmpanWarna } \\
\text { Merah Muda (Y) }\end{array}$ & $\begin{array}{c}\text { D } \\
(\mathrm{X}-\mathrm{Y})\end{array}$ & $\mathrm{D}^{2}$ \\
\hline 1 & $06.05-08.00$ & 4 & 1 & 3 & 9 \\
2 & $08.05-10.00$ & 3 & 1 & 2 & 4 \\
3 & $10.05-12.00$ & 5 & 3 & 2 & 4 \\
4 & $12.05-14.00$ & 4 & 2 & 2 & 4 \\
5 & $14.05-16.00$ & 5 & 2 & 3 & 9 \\
6 & $16.05-18.00$ & 4 & 1 & 15 & 39 \\
\hline Total & \multicolumn{7}{c}{10} & 1.67 & \\
\hline Rerata & & 4.17 & & \\
\hline
\end{tabular}

Fujaya (2002) menyatakan bahwa untuk ikan laut absorbsi pigmen utama dari cahaya yang tiba di mata ikan adalah panjang gelombang cahaya biru yang tercatat sebesar 4550-4920 Amstrong $\left(1 \AA=10^{-10} \mathrm{~m}\right)$. Sehingga dapat menarik ikan mendekati pancing. Selain warna umpan yang menyebabkan ikan terpikat ada kemungkinan pengaruh juga dari kilauan dari umpan serta gerak umpan dalam air (Baskoro dkk., 2011).

\section{KESIMPULAN}

1. Hasil tangkapan pancing tonda di perairan Teluk Manado dengan menggunakan umpan buatan dari kain sutra berwarna biru ternyata secara signifikan lebih banyak dari umpan buatan dengan kain sutra berwarna merah muda.

2. Hasil tangkapan pancing tonda di perairan Teluk Manado terdiri dari jenis ikan tongkol 
sebanyak 27 ekor dengan ukuran berat rata-rata $0,2 \mathrm{~kg}$, ikan selar sebanyak 1 ekor dengan berat rata-rata $0,1 \mathrm{~kg}$ ikan cakalang sebanyak 7 ekor dengan berat rata-rata $1,54 \mathrm{~kg}$.

\section{DAFTAR PUSTAKA}

Ayodhyoa, A.U. 1981. Metode Penangkapan Ikan. Yayasan Dewi Sri, Bogor.

Baskoro, M., A. Suherman. 2009. Teknologi Penangkapan Ikan dengan Cahaya. Badan Penerbit Undip, Semarang.

Baskoro, M., A. Taurusman, H. Sudirman. 2011. Tingkah Laku Ikan Hubungannya dengan Teknologi Perikanan Tangkap. CV. Lubuk Agung, Bandung.
Ferno, A. dan S. Olsen. 1994. Marine Fish Behaviour in Capture and Abundance Estimation. Fishing News Book Ltd., London.

Fujaya, Y. 2002. Fisiologi Ikan. Dasar Pengembangan Teknologi Perikanan Proyek Peningkatan Penelitian Pendidikan Tinggi, Departemen Pendidikan Nasional.

Hela, I. Dan T. Laevastu. 1993. Fisheries Oceanography. Fishing News Book Ltd., London.

Monintja, D.R. dan Zulkarnain. 1995. Analisis dampak pengoperasian rumpon tipe Philippine di Perairan ZEE terhadap perikanan cakalang di perairan territorial Selatan Jawa dan Utara Sulawesi. Fakultas Perikanan IPB, Bogor.

Von Brandt, A. 1984. Fish Catching Methods of The World. Fishing News Books Ltd., London. 